\title{
Article \\ Gender-Dependent Deregulation of Linear and Circular RNA Variants of HOMER1 in the Entorhinal Cortex of Alzheimer's Disease
}

\author{
Amaya Urdánoz-Casado ${ }^{1}{ }^{\mathbb{D}}$, Javier Sánchez-Ruiz de Gordoa ${ }^{1,2}$, Maitane Robles ${ }^{1}$, Blanca Acha ${ }^{1}$, Miren Roldan ${ }^{1}$, \\ María Victoria Zelaya ${ }^{3} \mathbb{D}$, Idoia Blanco-Luquin ${ }^{1} \mathbb{D}$ and Maite Mendioroz ${ }^{1,2, * \mathbb{D}}$
}

1 Neuroepigenetics Laboratory-Navarrabiomed, Complejo Hospitalario de Navarra-IdiSNA (Navarra Institute for Health Research), Universidad Pública de Navarra (UPNA), Pamplona, 31008 Navarra, Spain; amaya.urdanoz.casado@navarra.es (A.U.-C.); jsruizdegordoa@gmail.com (J.S.-R.d.G.); maitane.robles.solano@navarra.es (M.R.); blancacha02@hotmail.com (B.A.); mroldana@navarra.es (M.R.); iblancol@navarra.es (I.B.-L.)

2 Department of Neurology, Complejo Hospitalario de Navarra-IdiSNA (Navarra Institute for Health Research), Pamplona, 31008 Navarra, Spain

3 Department of Pathology, Complejo Hospitalario de Navarra-IdiSNA (Navarra Institute for Health Research), Pamplona, 31008 Navarra, Spain; mv.zelaya.huerta@navarra.es

* Correspondence: maitemendilab@gmail.com; Tel.: +34-848422677

\section{check for}

updates

Citation: Urdánoz-Casado, A.; Sánchez-Ruiz de Gordoa, J.; Robles, M.; Acha, B.; Roldan, M.; Zelaya, M.V.; Blanco-Luquin, I.; Mendioroz, M. Gender-Dependent Deregulation of Linear and Circular RNA Variants of HOMER1 in the Entorhinal Cortex of Alzheimer's Disease. Int. J. Mol. Sci. 2021, 22, 9205. https://doi.org/ $10.3390 /$ ijms 22179205

Academic Editor: Nicoletta Potenza

Received: 10 June 2021

Accepted: 23 August 2021

Published: 26 August 2021

Publisher's Note: MDPI stays neutral with regard to jurisdictional claims in published maps and institutional affiliations.

Copyright: (c) 2021 by the authors. Licensee MDPI, Basel, Switzerland This article is an open access article distributed under the terms and conditions of the Creative Commons Attribution (CC BY) license (https:// creativecommons.org/licenses/by/ $4.0 /)$

\begin{abstract}
The HOMER1 gene is involved in synaptic plasticity, learning and memory. Recent studies show that circular RNA derived from HOMER1 (circHOMER1) expression is altered in some Alzheimer's disease (AD) brain regions. In addition, HOMER1 messenger (mRNA) levels have been associated with $\beta$-Amyloid $(A \beta)$ deposits in brain cortical regions. Our aim was to measure the expression levels of HOMER1 circRNAs and their linear forms in the human AD entorhinal cortex. First, we showed downregulation of HOMER1B/C and HOMER1A mRNA and hsa_circ_0006916 and hsa_circ_0073127 levels in AD female cases compared to controls by RT-qPCR. A positive correlation was observed between HOMER1B/C, HOMER1A mRNA, and hsa_circ_0073128 with HOMER1B/C protein only in females. Global average area of $A \beta$ deposits in entorhinal cortex samples was negatively correlated with HOMER1B/C, HOMER1A mRNA, and hsa_circ_0073127 in both genders. Furthermore, no differences in DNA methylation were found in two regions of HOMER1 promoter between AD cases and controls. To sum up, we demonstrate that linear and circular RNA variants of HOMER1 are downregulated in the entorhinal cortex of female patients with AD. These results add to the notion that HOMER1 and its circular forms could be playing a female-specific role in the pathogenesis of AD.
\end{abstract}

Keywords: Alzheimer's disease; entorhinal cortex; HOMER1; sleep deprivation; circRNA; mRNA; calcium; synapses; Amyloid beta; gender; female

\section{Introduction}

Alzheimer's disease (AD) is a chronic, progressive and, for the time being, irreversible neurodegenerative process that is the leading cause of age-related dementia [1]. It is characterized by extracellular accumulation of amyloid plaques and intraneuronal tau neurofibrillary tangles causing loss of synapses and synaptic plasticity, thus impairing learning and memory [2-5]. It is further known that alterations in the homeostasis of glutamate and other ions such as $\mathrm{Ca}^{2+}$ are involved in the pathogenesis of $\mathrm{AD}[5,6]$.

Extracellular and intracellular $\beta$-Amyloid $(\mathrm{A} \beta)$ accumulation has been described in postmortem AD brains. A $\beta$ peptide interferes with channels and receptors that regulate neuronal fundamental characteristics such as excitability and synapses [7]. In AD brains, it has been shown that aberrant excitability and synapses may be due to the interaction of $A \beta$ with channels and receptors located at the synapse [7,8]. In this scenario, HOMER protein 
homolog 1 (HOMER1) gene plays a crucial role as a linker between neuronal channels and receptors. HOMER1 belongs to HOMER family proteins which are involved in postsynaptic density (PSD) forming links between receptors, channels and other scaffolding proteins [9]. HOMER family consists of three members (HOMER1, 2,3) with different isoforms each due to alternative splicing [10].

HOMER1 has different messenger RNAs (mRNA) variants which can be grouped into long variants such as HOMER1B and HOMER1C and a short variant known as HOMER1A [11]. The main difference between them is the absence of exons 7 and 8 [12,13] and, in terms of protein expression, the absence of Coiled Coil domain (CC domain) in the short variant $[8,14]$. HOMER1 protein structure consists of an amino-terminal region containing 1-175 amino acids (EVH1 domain) and a proline-containing motif (Pmotif) $[8,10]$. Moreover, only long HOMER protein isoforms dimerize and bind through the CC domain to numerous components of postsynaptic density, such as Group1 metabotropic glutamate receptors (mGluR1), N-Methyl-D-aspartate (NMDA) receptor scaffolding, ankyrin repeat domains proteins (SHANK), and other receptors to regulate calcium signaling in excitatory synapses $[8,11,15]$. It is also well known that neural activity modulates gene expression by modifying alternative mRNA splicing, which in turn may change protein properties and therefore its function [14]. Hence, HOMER1A is encoded by an immediate-early gene (IEG), and its expression increases rapidly after neuronal activation [8]. In addition, the lack of the $\mathrm{CC}$ domain causes HOMER1A to act as a dominant-negative regulator of HOMER1B/C scaffolding capacity $[11,15]$.

HOMER1 mRNA isoforms are mainly expressed in the nervous system and play crucial roles in synaptic plasticity and signal transduction via their dynamic distribution at the postsynaptic level [8]. Changes in PSD formation induce alterations of the density and shape of the dendritic spines, impairing both learning and memory. Furthermore, the abnormal activation of glutamate receptor signaling and other cation channels are associated with a number of neurological diseases [8] such as mental retardation syndromes, schizophrenia, autism spectrum disorders or $\mathrm{AD}[8,9]$. HOMER1B/C regulates the neuronal surface clustering of mGluRs, and treatment of fronto-cortical neurons with soluble $\mathrm{A} \beta$ results in rapid and significant thinning of the PSD and disassembly of HOMER1B/C synaptic clusters [8]. On another matter, HOMER1A, which is activity-dependent, has been suggested to regulate $\mathrm{A} \beta$ toxicity at the early stage of $\mathrm{AD}$, and reduced Homer1a mRNA expression has been found in amyloid precursor protein and presenilin-1(APP + PS1) transgenic mice [8]. Yamamoto et al. [7] suggested that HOMER1A expression could be a therapeutic approach to prevent, at least partially, $\mathrm{A} \beta$ toxicity at the early stage of AD.

In addition to HOMER1 linear RNA molecules, other RNA species have been described, such as HOMER1 circular RNAs (circRNAs). circRNAs are a novel class of noncoding RNA characterized by a covalent junction between the $3^{\prime}$ end and $5^{\prime}$ end, formed by a back-splicing process. From the same pre-mRNA precursor, mRNAs and circRNAs are originated by canonical splicing and alternative splicing [16-19]. Though circRNAs are expressed all throughout the body, it is in the brain, and specifically at the synapses, where they are most expressed [20-22]. Some researchers have observed that a disproportionate fraction of circRNAs are derived from host genes that code for synaptic proteins [23]. In addition, it is known that circRNAs are playing important roles in brain development and in neurological diseases. In fact, altered expression in circRNAs in AD, and a circHOMER1 transcript has been shown to be downregulated in different brain regions [24-26]. It is worth mentioning that this circHOMER1 also is downregulated in prefrontal cortex and pluripotent stem-cell-derived neuronal cultures from patients with schizophrenia and bipolar disorder [11]. Thus, circHOMER1 downregulation appears to be playing a role in synapses gene expression and cognitive flexibility [11].

Despite all these data, little is known about the expression of different HOMER1 mRNA and circRNA transcripts in human AD brains. The purpose of this work is to provide knowledge about the expression of linear and circular HOMER1 variants in the human $\mathrm{AD}$ entorhinal cortex, a brain region most vulnerable to the disease. We also seek 
to know whether epigenetic features, in particular DNA methylation levels, are altered in the promoter region of HOMER1 in the brain of AD patients.

\section{Results}

To our knowledge, no previous studies have investigated HOMER1 RNA variants expression in the human AD entorhinal cortex. As described above, HOMER1A protein acts as a negative regulator of HOMER1B/C, and both HOMER1A and HOMER1B/C play crucial roles in synaptic plasticity and signal transduction, processes that are altered in $\mathrm{AD}$ [8]. We therefore consider it interesting to study separately the expression of $H O M E R 1 B / C$, which contains exons coding for the CC domain, and HOMER1A, which lacks these exons, in human entorhinal cortex affected by AD.

\subsection{HOMER1 mRNA Variants Are Downregulated in Entorhinal Cortex of AD Female Cases Compared to Controls}

Firstly, to test if HOMER1 variants were differentially expressed in the entorhinal cortex of AD cases compared to controls, we measured HOMER1 mRNA expression levels by RT-qPCR. All RNA samples passed the RNA quality threshold, so $28 \mathrm{AD}$ cases were compared to 16 controls (Supplementary Materials Table S1). To distinguish long from short HOMER1 variant, specific primer sets were designed to be located at different exons (Figure 1A and Table 1). Following this approach, we found that HOMER1B/C mRNA levels showed a 0.61 fold decrease $(p$-value $<0.01)$ in AD cases compared to controls. HOMER1A mRNA expression levels were also reduced by 0.605 fold $(p$-value $<0.01)$ in AD cases compared to controls (Supplementary Materials Figure S1A).

Next, we wanted to know whether these results were biased by age or gender, since we identified differences in age and gender between AD patients and controls (Supplementary Materials Table S2). For this purpose, a univariate general linear model adjusted by age and gender was developed indicating that gender had influence on AD status $(p$-value $=0.003)$ while age did not $(p$-value $=0.486)$. To further assess any genderrelated variation in HOMER1 expression, the sample set was subdivided by gender and the analysis was redone in females $(n=23)$ and males $(n=21)$. Following this approach, we found females showed a significant decrease by 0.4 fold of $H O M E R 1 B / C$ and 0.55 fold of HOMER1A expression in AD samples compared to controls ( $p$-value $<0.0001$ and $p$-value $<0.01$, respectively). However, no significant decrease was shown in male samples ( $p$-value $=0.387$ and $p$-value $=0.314$, respectively) (Figure 1B).

We then sought to determine whether HOMER1 mRNA variants expression was related to the severity of neuropathological changes of $\mathrm{AD}$. When we analyzed expression according to the $\mathrm{ABC}$ score in females, HOMER1B/C mRNA showed significant differences, being its expression decreased in low $(p$-value $<0.01)$ and high $(p$-value $<0.05) \mathrm{ABC}$ cases versus controls (Supplementary Materials Figure S2A). On the contrary, no significant differences were found in the male subgroup. Regarding HOMER1A mRNA variant, no changes in expression levels were shown in either women or men.

Although $A B C$ score is a very informative neuropathological score which includes Braak and Braak staging, we decided to analyze the severity also by Braak and Braak criteria, as it is still commonly used by investigators. In females, we found that $H O M E R 1 B / C$ mRNA expression levels were decreased in Braak I-II stage compared to controls $(p$-value $<0.05)$ and in Braak V-VI stage compared to controls ( $p$-value $<0.05)$ (Supplementary Materials Figure S2B), accordingly with ABC score results. 


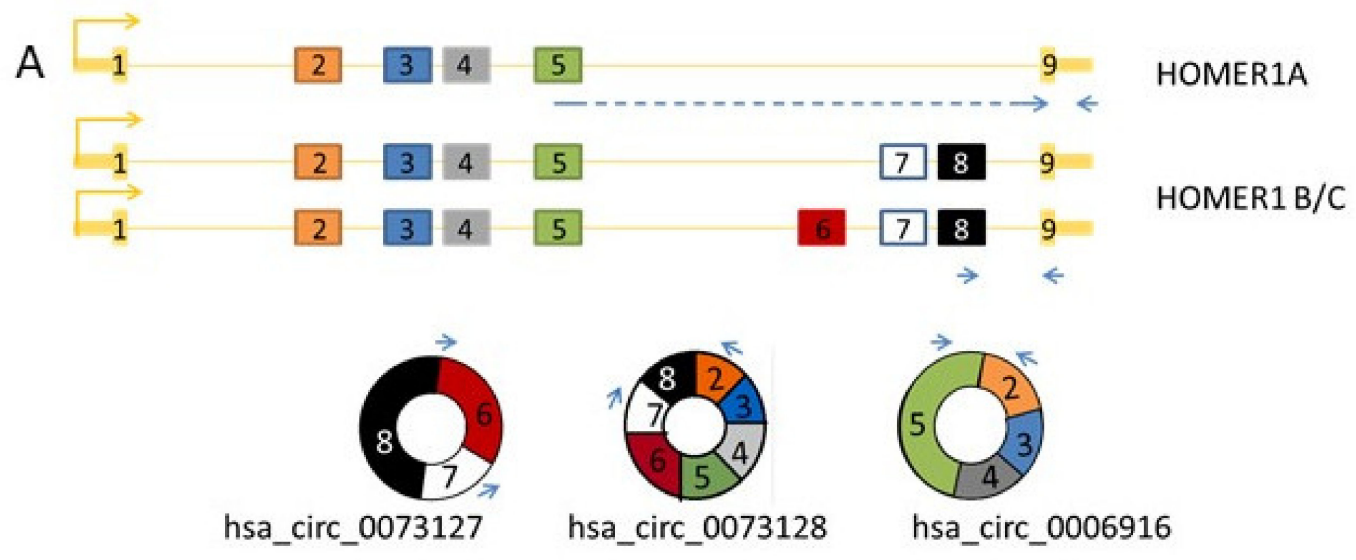

B
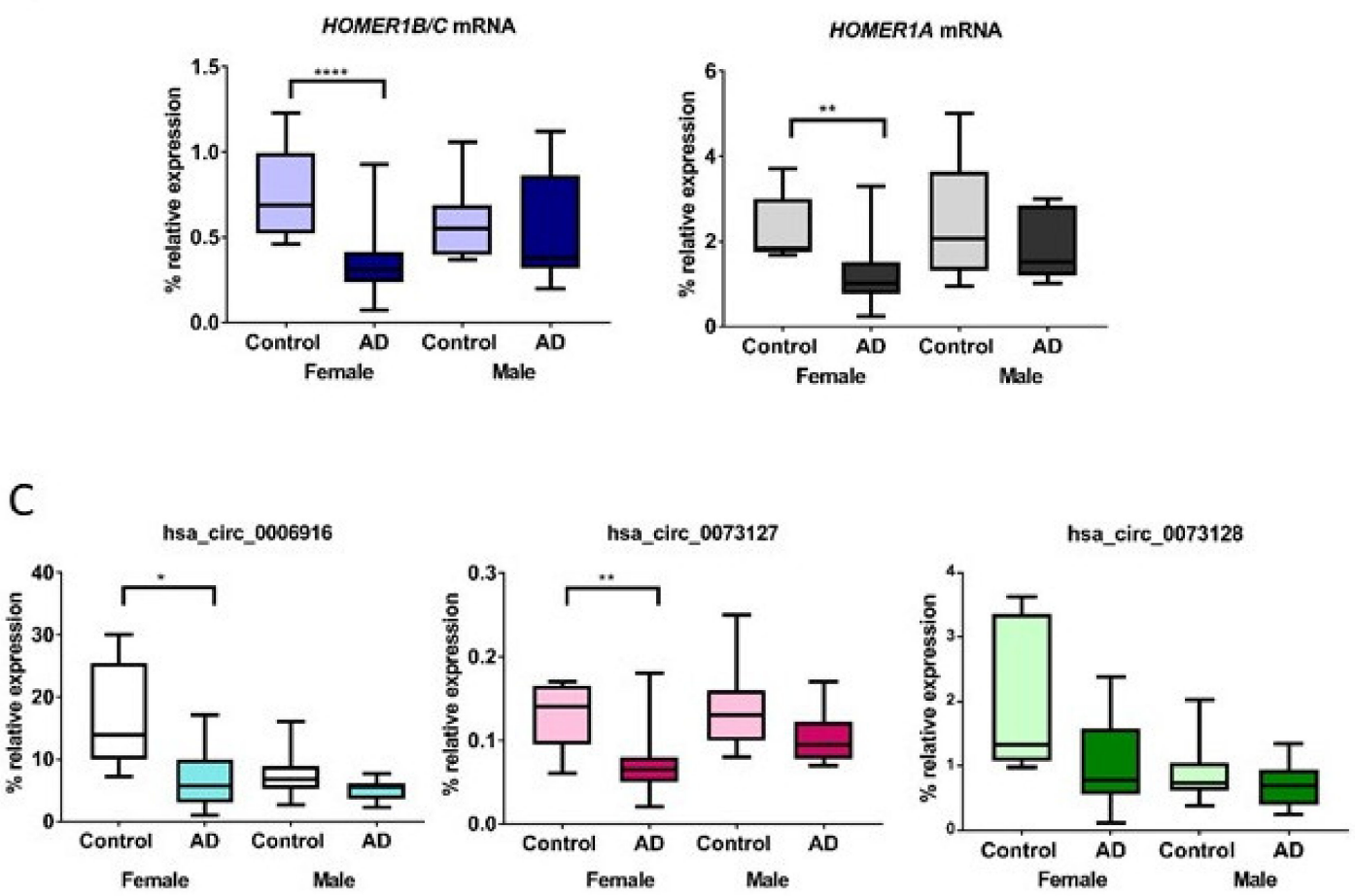

Figure 1. HOMER1 and circHOMER1 variants expression. (A) Gen map for each linear and circular HOMER1 RNA form. Boxes represent exons and arrows show where primers are located. (B,C) Box-plot represents the percentage of HOMER1 and circHOMER1 expression relative to geometric mean of GAPDH and ACTB housekeeping genes expression in females $(n=23)$ and males $(n=21) .{ }^{*} p$-value $<0.05 ;{ }^{* *} p$-value $<0.01 ; * * *$-value $<0.0001$.

Table 1. Primers sets.

\begin{tabular}{|c|c|c|}
\hline & Forward $5^{\prime}->3^{\prime}$ & Reverse $5^{\prime}->3^{\prime}$ \\
\hline HOMER1A & CACATAGGAAGTAGAAATTCGGAAC & TTTCACTTTCCTTAGCTGCATTC \\
\hline HOMER1B/C & CAGAGAACTACAAGAACAGAGGG & GACGTTGCTCTAAGTCAGACAG \\
\hline hsa_circ_0006916 & TTTGGAAGACATGAGCTCGA & AAGGGCTGAACCAACTCAGA \\
\hline hsa_circ_0073127 & GAAACTACAGTTCAGCAATCAGC & AAGTTCAGTCACCCGCTTGT \\
\hline hsa_circ_0073128 & AGCCAAGCAAATGCAGTACA & TGTGTTTGGGTCAATTTGGA \\
\hline Bis-HOMER1_1 & GATTTTATTTTTTTTAGTTTTTTTT & TAАСТСТАТААТТСАТТСАТТСТСС \\
\hline Bis-HOMER1_2 & TTTTTTAGGTAAAATGATTTTTTTT & ААТТАССТААСТСТСССТАААТАТС \\
\hline
\end{tabular}




\subsection{HOMER1 circRNA Variants Are Downregulated in Entorhinal Cortex in AD Female Cases Compared to Controls}

Next, we wanted to test whether HOMER1 circRNAs expression levels were also altered in $\mathrm{AD}$ entorhinal samples in $\mathrm{AD}$ females. For the purpose of this study, we selected three circRNAs from circInteractome [27], hsa_circ_0006916 and hsa_circ_0073128, which had been previously described in AD brains [24,26], and hsa_circ_0073127, which arises from exons 7 and 8 that are not included in the HOMER1A linear transcript. Thus, we designed specific primer sets to amplify and quantify each of these three HOMER1 circRNAs (Figure 1A and Table 1) and Sanger sequencing was used to confirm the backsplice junction of the identified circRNAs.

We observed that hsa_circ_0006916 and hsa_circ_0073127 expression levels were downregulated in the entorhinal cortex of female AD cases compared to female controls (fold-change $=0.39, p<0.05$ and fold-change $=0.46, p<0.01$, respectively) (Figure 1C). By contrast, hsa_circ_0073128 expression level did not change, neither change any circHOMER1s in the male subgroup.

We also analyzed circHOMER1s expression according to $\mathrm{ABC}$ score and gender subgroup. In females, the three circHOMER1s expression levels showed significant differences, being its expression decreased in low ABC cases versus controls (hsa_circ_006916, $p$-value $<0.01$; hsa_circ_0073127, $p$-value $<0.05$; and hsa_circ_0073128, $p$-value $<0.05$ ) (Supplementary Materials Figure S2A). No differences in HOMER1 circRNAs according to ABC score were found in the male subgroup. When considering only Braak staging (Supplementary Materials Figure S2B), no differences were observed for any circHOMER1 in either women or men.

\subsection{Proportional Decreases in HOMER1 $m R N A$ and circRNAs Variants Expression Levels in $A D$ Female Cases Compared to Controls}

To answer the question of whether or not the change in expression levels between controls and $\mathrm{AD}$ female cases is proportional across the different mRNA HOMER1 variants and circRNAs, we used a univariate general linear model. In this model the dependent variable was the expression of the different HOMER1 RNA transcripts and the predictors were the specific RNA variants and disease status (AD or control).

Overall, expression of all variants together was $56.43 \%$ lower in $\mathrm{AD}$ females compared to control cases. The variant most highly expressed was hsa_circ_0006916, even more highly expressed than linear HOMER1 variants (Supplementary Materials Figure S3A,B). Furthermore, expression levels of variants were different among them. Considering HOMER1A as a reference, expression of $H O M E R 1 B / C$ was $70.81 \%$ lower, and hsa_circ_0073127 and hsa_circ_0073128 were expressed $93.81 \%$ and $18.92 \%$ less, respectively. On the contrary, hsa_circ_0006916 showed $440.01 \%$ higher expression compared to HOMER1A. However, no significant differences were shown in expression when we consider cases and each transcript together in the model, meaning that the decrease in expression of the different variants is proportional within AD female cases (Supplementary Materials Figure S3A,B). We conclude that relative expression ratios of each transcript are maintained even though they are significantly decreased in $\mathrm{AD}$ females compared to controls when studied independently.

\subsection{Correlation between HOMER1 Protein and RNA Expression Levels in the Entorhinal Cortex} of Females

In order to test if downregulation of HOMER1 mRNA in AD cases was related with protein levels, Western blot analysis was carried out in 15 entorhinal human samples: 6 controls ( 3 females) and 9 AD cases ( 6 females). We observed that HOMER1 B/C protein levels were downregulated in AD brain cases compared to controls (fold-change $=2.19$, $p$-value < 0.01) (Supplementary Materials Figure S4). However, when we re-performed the analysis by gender subgrouping neither female or male showed significant differences between controls and AD samples.

Next, we analyzed the correlation between HOMER1 RNA variants expression levels and protein expression levels by gender subgroup. We observed in females a posi- 
tive correlation between mRNA forms and protein expression of $H O M E R 1 B / C(\mathrm{r}=0.733$, $p$-value $<0.05)$ and a strong positive correlation between hsa_circ_0073128 and protein expression $(\mathrm{r}=0.883, p$-value $<0.01)$. However, we found no correlation between protein and any RNA expression levels in males.

\subsection{Correlation between DNA Methylation Levels in HOMER1 Promoter and RNA Expression Levels}

DNA methylation levels in regulatory regions of the genome are known to modulate the expression of related or nearby genes. To determine whether DNA methylation within the HOMER1 promoter region is related with HOMER1 expression and altered in the brain of $\mathrm{AD}$ patients, we explored two regions within the promoter of HOMER1 gene, one of them overlapping a $\mathrm{CpG}$ island. To this end, we used bisulfite sequencing cloning (Figure 2A) in genomic DNA isolated from entorhinal cortex of four AD cases and four controls.

\section{A}

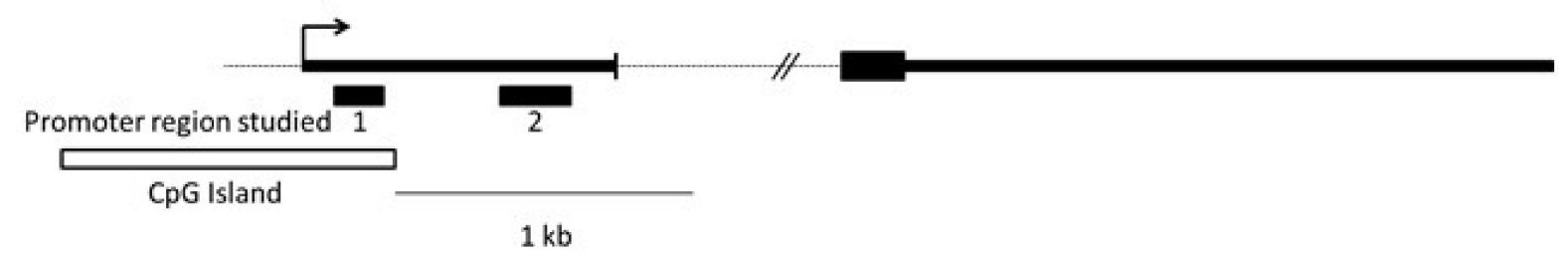

B

Promoter Region 1

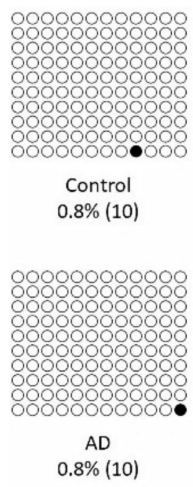

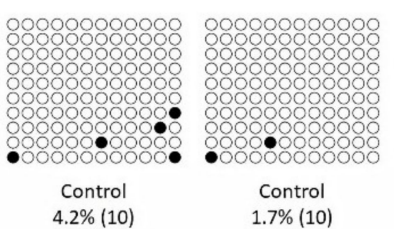

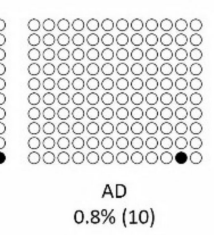

$1.7 \%(10)$

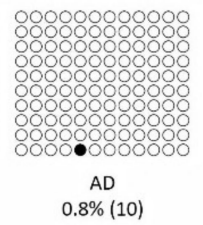

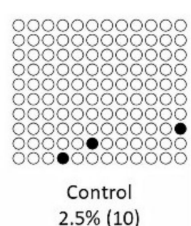

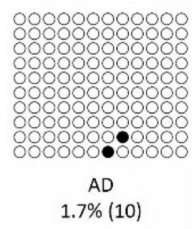

\section{Promoter Region 2}

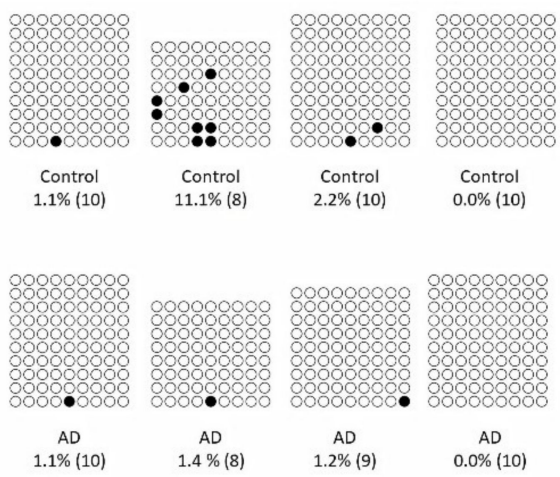

Figure 2. DNA methylation levels in entorhinal samples. (A) The graph shows genomic position of the amplicons (black boxes) assessed by bisulfite cloning sequencing within the exon 1 of HOMER1 gene. CpG island is represented by white box. (B) Bisulfite cloning sequencing for the two amplicons studied. Black and white circles denote methylated and unmethylated cytosines, respectively. Each column symbolizes a unique CpG site in the examined amplicon, and each line represents an individual DNA clone.

These regions showed low methylation levels (Figure 2B) as corresponding to genes actively expressed. We observed a positive correlation between DNA methylation levels of the promoter region overlapping the $\mathrm{CpG}$ island and mRNA expression levels of HOMER1A $(\mathrm{r}=0.889, p$-value $<0.001)$ and a statistical trend was found for HOMER1 B/C $(\mathrm{r}=0.741, p$-value $=0.057)$. On the other hand, no significant correlation was shown between HOMER1 circRNA variants and DNA methylation levels. In addition, no differences in DNA methylation were observed in either region between AD cases and controls. 


\subsection{Correlation of HOMER1 RNA Variants Expression Levels with A $\beta$ Deposits}

We next aimed to correlate HOMER1 RNA variants expression levels with the burden of $A \beta$ in the $A D$ brains. In the female group the global average area of $A \beta$ deposits in entorhinal cortex was negatively correlated with linear HOMER1 RNA variants levels (Table 2) and hsa_circ_0073127. Males also showed negative correlation between the global average area of $A \beta$ deposits in entorhinal cortex and linear $H O M E R 1 B / C$ and circRNAs.

Table 2. Correlation between global average area of $\mathrm{A} \beta$ deposits and HOMER1 linear RNAs and circRNAs expression levels. $(n=20) .{ }^{*} p$-value $<0.05$.

\begin{tabular}{|c|c|c|c|c|c|c|}
\hline Female & & HOMER1B/C & HOMER1A & hsa_circ_0073127 & hsa_circ_0073128 & hsa_circ_0006916 \\
\hline \multirow[t]{2}{*}{$\begin{array}{c}\text { global } \\
\text { average area } \\
\text { of } A \beta \\
\text { deposits }\end{array}$} & $\begin{array}{l}\text { correlation } \\
\text { coeficient } \\
\text { (Spearman's } \\
\text { Rho) }\end{array}$ & $-0.483 *$ & $-0.447^{*}$ & $-0.479 *$ & -0.005 & -0.038 \\
\hline & Sig. (bilateral) & 0.036 & 0.048 & 0.038 & 0.982 & 0.873 \\
\hline Male & & HOMER1B/C & HOMER1A & hsa_circ_0073127 & hsa_circ_0073128 & hsa_circ_0006916 \\
\hline \multirow[t]{2}{*}{$\begin{array}{c}\text { global } \\
\text { average area } \\
\text { of } A \beta \\
\text { deposits }\end{array}$} & $\begin{array}{l}\text { correlation } \\
\text { coeficient } \\
\text { (Spearman's } \\
\text { Rho) }\end{array}$ & $-0.487^{*}$ & -0.452 & -0.494 * & -0.473 * & $-0.486^{*}$ \\
\hline & Sig. (bilateral) & 0.041 & 0.059 & 0.037 & 0.047 & 0.041 \\
\hline
\end{tabular}

\section{Discussion}

In this study, we show that linear and specific circular variants of HOMER1 RNA are downregulated in the human entorhinal cortex of $\mathrm{AD}$ female patients while no changes are found in males. In addition, a positive correlation of HOMER1 linear RNAs and a circHOMER1 with protein expression was observed. Moreover, there is a negative correlation of HOMER1 RNA variants expression levels with $\mathrm{A} \beta$ burden in both genders at human entorhinal cortex. Our data also suggest that DNA methylation at the promoter region of HOMER1 is not altered in $\mathrm{AD}$ and therefore is probably not involved in regulating the lower expression of HOMER1 RNA observed in the disease.

The HOMER1 gene is expressed in the PSD mainly at glutamatergic synapses [15]. Due to alternative splicing two isoforms have been described; HOMER1B/C plays a role in synapses as a scaffolding protein, establishing connections between receptors involved, among other processes, in $\mathrm{Ca}^{2+}$ homeostasis [15]. Regarding HOMER1A, it is a negative regulator of $H O M E R 1 B / C$ scaffolding capacity. HOMER1 is considered an IEG, as it is induced in response to neuronal activity [9] and is a crucial gene for synapses plasticity and memory consolidation $[8,28]$.

The results of the present study are consistent with previous reports where deregulation of HOMER1 was described in brain tissue from other neurological conditions $[8,9,29]$. HOMER1A expression is downregulated in some particular brain areas in bipolar disorder, while in others is upregulated [29]. In schizophrenia, the HOMER1A/HOMER1B/C ratio was observed to be altered in hippocampus, being $H O M E R 1 B / C$ downregulated and HOMER1A upregulated [30]. In addition, brain ischemia seems to downregulate expression levels of HOMER1A and HOMER B/C [31]. However, to our knowledge, no previous report of gender-specific HOMER1 expression in brain tissue have been reported.

Since HOMER1 is a major component of synapses, it is not surprising that this gene is found altered in synaptopathies, including some of the above-mentioned disorders. Indeed, many neurological and psychiatric conditions show dysfunctional synapses. In the case of $\mathrm{AD}$, synapses are thought to be altered due to the toxic effect of amyloid peptides and tau protein tangles [32]. In fact, previous reports have suggested that Homer1a could be involved in $\mathrm{A} \beta$ toxicity at the early stage of $\mathrm{AD}$ [8]. Even a role in processing $\mathrm{A} \beta$ has been proposed for Homer1a based on studies performed in other animal models [33]. In our 
study, we observed in both genders a negative correlation between the burden of $A \beta$ and expression levels of all the linear transcripts and some circRNAs. On the whole, these data suggest a relationship between the HOMER1 gene and $A \beta$ deposition and support the idea that HOMER1 might be involved in A $\beta$ processing, as other authors have proposed [33]. Nevertheless, the observation of reduced expression levels of HOMER1 RNA transcripts in brain tissue may well be a consequence of reduced synapsis typical of $\mathrm{AD}$ and not the other way around. To elucidate whether $A \beta$ or tau have an effect on neuronal HOMER1 expression, or if HOMER1 definitely influences $\mathrm{A} \beta$ deposition, in vitro or in vivo experiments are needed, and the present study only shows an association between both variables.

The present study shows an intriguing result, being HOMER1 downregulated only in the brain of female patients with AD. This precludes extending the conclusions to men with AD. However, it is well known that a gender bias has long been observed in AD, with women being at the highest risk of developing the disease [34,35]. Nevertheless, the molecular basis of this gender bias is still largely unknown. Interestingly, estradiol seems to prevent hippocampal neuronal death with exposure to glutamate [36]. Additionally, some authors have observed a female-selective reduction in GluR2 AMPA glutamate receptor subunit expression in the nucleus basalis neurons in $\mathrm{AD}$, suggesting that cholinergic nucleus basalis neurons may be at greater risk for degeneration during the progression of the disease in females [37]. The cause of a female bias in AD is still intriguing and brain molecular changes underlying $\mathrm{AD}$ pathology may help to better understand this epidemiological bias. Indeed, to focus on gender differences in AD has been strongly recommended by experts in the field [38]. In this line, sex-specific genetic variants in AD biomarkers have been also reported [39].

HOMER1A has been involved in glutamate-dependent synaptic plasticity [40]. Increasing evidence points to glutamate-mediated excitotoxicity in development of neuronal death in $\mathrm{AD}$ and other neurodegenerative conditions [41]. A prolonged increase in glutamate over time triggers a postsynaptic response, and thus, an increase in $\mathrm{Ca}^{2+}$ concentration in neurons being neurotoxic [5]. Importantly, elucidation of the molecular bases underlying synaptopathies may help to discovered new drug targets for these disorders, including AD. In this scenario, Homer1a has been shown to be upregulated by memantine [40], which is a non-competitive NMDA receptor antagonist used to alleviate clinical symptoms of AD [40]. Accordingly, Homer 1 is also altered in the hippocampus of a murine model used to investigate the effectiveness of acetylcholinesterase inhibitors in the treatment of AD [42]. As we observed a decrease in the long isoform, $H O M E R 1 B / C$, at early stages of $A D$, drugs that increase HOMER1A or HOMER1B/C brain expression would be interesting to be explored in AD female patients.

Most interestingly, a relationship between sleep deprivation and A $\beta$ brain burden has been recently recognized [43-46]. Sleep disturbance is related to cognitive impairment and may be a risk factor for $\mathrm{AD}$ by increasing $\mathrm{A} \beta$ deposition [45]. HOMER1 arises as a candidate to explain, at least in part, the link between sleep alterations and AD dementia, since HOMER1 is a gene closely related to sleep and a crucial marker of sleep deficit. For instance, it is well known that Homer1a expression undergoes circadian regulation in the brain $[47,48]$ and Homer1a is thought to mediate the cross-talk between circadian inputs and neuronal activity. Recently, it has been described that HOMER1 mRNA expression is high at baseline in human brain regions where $A \beta$ accumulates when sleep is altered [49].

One of the roles of circRNAs is to regulate linear RNA transcription (including its host RNA) but also other epigenetics mechanisms could be regulating mRNA and circRNA expression. In cancer, $\mathrm{CpG}$ promoter hypermethylation has been shown to downregulate circRNA and its host linear RNA expression [50]. Interestingly, it has been described that in fear conditions or depression there exists an epigenetic modulation of HOMER1 transcription regulation [51,52]. It is also worth mentioning that changes in epigenetic marks have been observed in human AD brains [53,54]. Alterations in CpG methylation could be playing a role in the different circular and linear HOMER1 variants expression 
in AD. We explored the status of DNA methylation at the promoter region of HOMER1 and found a positive relationship between methylation levels and mRNA expression of HOMER1A variant. However, we did not find significant correlation with HOMER1 B/C or circRNA expression levels or any significant change between patients and controls. This may suggest that expression of HOMER1 linear and circular transcripts are not regulated on the whole by DNA methylation. Nevertheless, we should be very cautious with this idea since the sample size is small and only two amplicons have been surveyed, and methylation at other regions such as enhancers or alternative promoters could be playing a part in modulating HOMER1 expression. To assess whether DNA methylation within HOMER1 promoter is involved in downregulation of HOMER1 transcripts in AD cases, further experiments would be required.

It is interesting that we also found a consistent decreased expression of two circRNAs in the entorhinal cortex of AD female patients, i.e., hsa_circ_0006916 and hsa_circ_0073127; hsa_circ_0006916 was first described as a circRNA derived from the synaptic HOMER1 gene [23]. Our result is concordant with a previous study where a RNAseq experiment was performed in human parietal lobe tissue to identify and quantify circRNAs related to AD [24]. Interestingly, hsa_circ_006916 was also downregulated in the parietal and frontal cortex of AD patients $[24,25]$. A more recent study also found decreased expression levels of hsa_circ_006916 in the anterior prefrontal cortex, inferior frontal gyrus and parahippocampal gyrus, and of hsa_circ_0073128 in the anterior prefrontal cortex [26]. Intriguingly, in the latter study hsa_circ_006916 showed no differential changes in AD in the superior temporal lobe and neither did hsa_circ_0073128 in the superior temporal lobe, inferior frontal gyrus and parahippocampal gyrus. In our study, hsa_circ_0073127 arises as a novel circRNA consistently involved in $\mathrm{AD}$, at least in females, since it was downregulated in $\mathrm{AD}$ female cases. Moreover, we want to highlight that hsa_circ_006916 was the majoritarian variant in HOMER1 expression levels, with significantly higher levels than linear HOMER1 RNA variants. Other genes have been previously described to show a predominant expression of a circRNA variant compared to its mRNA cognates, including the AD-related CDR1 gene $[20,23,24]$. It is very relevant that circRNAs seem to be more enriched in synaptic processes than their linear isoforms, and HOMER1, as a synaptic gene, seems to follow this rule [23]. The results of our study and others point to a coordinated HOMER1 circRNA downregulation across different brain regions. Our results in the entorhinal cortex, a brain area where neuropathological changes of AD start, may also suggest an early involvement of HOMER1 changes, including its circRNA variants, in the development of the disease in females. However, we should be very cautious, since robustness of the stratified analysis may be limited by sample size, and this is only an observational study that precludes drawing conclusions about mechanistic relationships. Further studies on HOMER1 expression in other brain series would add evidence to definitively unravel the real involvement of the HOMER1 gene in AD pathology.

In conclusion, specific HOMER1 circular and linear RNA transcripts are decreased in the entorhinal cortex of AD patients, suggesting that this synapse-related gene may play a crucial role in the early development of the disease. Moreover, we describe a novel circRNA, hsa_circ_0073127, associated with AD pathology in a gender-specific manner. Gender-specific analysis may improve understanding of AD pathogenesis and reinforce the use of personalized medicine. As is the case of HOMER1, circRNA species of specific genes seem to be associated with amyloid deposits, which opens the path for studying these molecules as biomarkers of synaptopathies or even novel pharmacological targets for AD.

\section{Materials and Methods}

\subsection{Human Entorhinal Samples}

Brain entorhinal cortex samples from $28 \mathrm{AD}$ patients and 16 controls were provided by Navarrabiomed Brain Bank. After death, half brain specimens from donors were cryopreserved at $-80^{\circ} \mathrm{C}$. Neuropathological examination was completed following the 
usual recommendations [55] and according to the updated National Institute on AgingAlzheimer's Association guidelines [56].

Assessment of $A \beta$ deposition was carried out by immunohistochemical staining of paraffin-embedded sections ( $3-5 \mu \mathrm{m}$ thick) with a mouse monoclonal (S6 F/3D) anti-A $\beta$ antibody (Leica Biosystems Newcastle Ltd., Newcastle upon Tyne, United Kingdom). Evaluation of neurofibrillary pathology was performed with a mouse monoclonal antibody anti-human PHF-TAU, clone AT-8 (Tau AT8) (Innogenetics, Gent, Belgium), which identifies hyperphosphorylated tau ( $p$-tau) [57]. The reaction product was visualized using an automated slide immunostainer (Leica Bond Max) with Bond Polymer Refine Detection (Leica Biosystems, Newcastle Ltd., Newcastle upon Tyne, United Kingdom). Other protein deposits, such as synuclein deposits, were ruled out by a monoclonal antibody against $\alpha$-synuclein (NCL-L-ASYN; Leica Biosystems, Wetzlar, Germany). The staging of AD was performed by using the $\mathrm{ABC}$ score according to the updated National Institute on AgingAlzheimer's Association guidelines [56]. ABC score combines histopathologic assessments of $A \beta$ deposits determined by the method of Thal (A) [56], staging of neurofibrillary tangles by Braak and Braak classification (B) [57], and scoring of neuritic plaques by the method of CERAD (Consortium to Establish A Registry for Alzheimer's Disease) (C) [58] to characterize $\mathrm{AD}$ neuropathological changes. Thus, the $\mathrm{ABC}$ score shows three levels of $\mathrm{AD}$ neuropathological severity: low, intermediate, and high. A summary of the characteristics of subjects considered in this study is shown in Supplementary Materials Table S1.

\subsection{Quantitative Assessment of A $\beta$ Deposits in Brain Tissues}

In order to quantitatively assess the $A \beta$ burden for further statistical analysis, we applied a method to quantify protein deposits. This method generates a numeric measurement that represents the extent of $A \beta$ deposition. Sections of the entorhinal cortex were examined after performing immunostaining with anti-A $\beta$ antibody as described above in human entorhinal samples. Three pictures were obtained for each immunostained section by using an Olympus BX51 microscope at $\times 10$ magnification power. Focal deposit of $A \beta$, as described by Braak and Braak (neuritic, immature, and compact plaque) [57], was manually determined and was further edited and analyzed with the Image software. Then, $\mathrm{A} \beta$ plaque count, referred to as amyloid plaque score (APS) and total area of $\mathrm{A} \beta$ deposition were automatically measured by ImageJ and averaged for each section.

\subsection{RNA Isolation and RT-qPCR}

Total RNA was isolated from entorhinal cortex with RNAeasy Lipid Tissue mini-Kit (QIAGEN, Redwood City, CA, USA) following the manufacturer's instructions. Genomic DNA was removed with recombinant DNase (TURBO DNA-free ${ }^{\mathrm{TM}} \mathrm{Kit}$, Ambion Inc., Austin, TX, USA). Concentration and purity of RNA were both evaluated with NanoDrop spectrophotometer. Complementary DNA (cDNA) was reverse transcribed from $500 \mathrm{ng}$ total RNA with SuperScript ${ }^{\circledR}$ III First-Strand Synthesis Reverse Transcriptase (Invitrogen, Carlsbad, CA, USA) after priming with random primers. RT-qPCR reactions were performed in triplicate with Power SYBR Green PCR Master Mix (Invitrogen, Carlsbad, CA, USA) in a QuantStudio 12K Flex Real-Time PCR System (Applied Biosystems, Foster City, CA, USA) and repeated twice within independent cDNA sets. Sequences of primer pairs were designed using Real Time PCR tool (IDT, Coralville, IA, USA) and Primer3 software and are listed in Table 1. Relative expression level of mRNA in a particular sample was calculated as previously described [59] and geometric mean of GAPDH and ACTB genes were used as the reference to normalize expression values.

\section{4. circRNA Confirmation by Sanger Sequencing}

circRNA candidate bands were selected after 1.8\% agarose gel electrophoresis of RTqPCR products. Bands purification was made with Wizard ${ }^{\circledR}$ SV Gel and PCR Clean-Up System (Promega, Madison, WI, USA). Next, Sanger sequencing was performed and UCSC Genome Browser software Blat-tool was used for sequence alignment [60,61]. 


\subsection{HOMER1 Protein Expression Analysis by Western Blot}

Human entorhinal cortex tissue from patients and control samples was lysed with $100 \mu \mathrm{L}$ lysis buffer containing urea, thiourea, and DTT. After centrifugation at 35,000 rpm for $1 \mathrm{~h}$ at $15^{\circ} \mathrm{C}$, extracted proteins were quantified following the Bradford Protein Assay (Bio-Rad, Hercules, CA, USA) by using a spectrophotometer. Next, $10 \mu \mathrm{g}$ of protein per sample were resolved in 4-15\% Criterion TGX stain-free gels (Bio-Rad, Hercules, CA, USA) and electrophoretically transferred onto nitrocellulose membranes using a Transblot Turbo transfer system ( $25 \mathrm{~V}, 7 \mathrm{~min}$ ) (Bio-Rad, Hercules, CA, USA). Equal loading of the gel was assessed by stain-free digitalization and by Ponceau staining. Membranes were probed with mouse anti-human HOMER1 B/C primary antibody (Santa Cruz sc25271; 1:250) (Santa Cruz Biotechnology Inc., Dallas, TX, USA) in 5\% nonfat milk and incubated with peroxidase-conjugated anti-mouse secondary antibody (Bio-Rad, 170-6516, 1:2000) (Bio-Rad, Hercules, CA, USA). Immunoblots were then visualized by exposure to an enhanced chemiluminescence Clarity Western ECL Substrate (Bio-Rad, Hercules, CA, USA) using a ChemidocMP Imaging System (Bio-Rad, Hercules, CA, USA). Expression levels of HOMER1 B/C were standardized by the corresponding band intensity of mouse anti-human GAPDH (Calbiochem; cb1001, 1:10,000).

\subsection{HOMER1 Methylation by Bisulfite Cloning Sequencing}

Bisulfite-converted genomic DNA was used to study promotor methylation levels of HOMER1 gene. Primer pair sequences were designed by MethPrimer [62] and are listed in Table 1. PCR products were cloned using the TopoTA Cloning System (Invitrogen, Carlsbad, CA, USA), and a minimum of 10-12 independent clones were sequenced for each examined subject and region. Methylation graphs were obtained by using QUMA software [63].

\subsection{Statistical Data Analysis}

Statistical analysis was performed with SPSS 25.0 (IBM Corp., Armonk, NY, USA). Before performing differential analysis, we checked whether continuous variables were normally distributed, as per one-sample Kolgomorov-Smirnov test and the normal quantilquantil (QQ) plots. Statistical significance was set at $p$-value $<0.05$. Mann-Whitney $U$ test was used to assess statistical difference of the following variables: mRNA, circRNAs and protein levels.

A univariate general linear model adjusted by age and gender was used to know whether the difference of the mRNA and circRNAs expression levels were biased by age or gender, the values of expression levels were transformed by using $\log _{10}(X)$ to meet the conditions of normality. Kruskal-Wallis one-way analysis of variance (ANOVA) was used to analyze differences in the expression levels of HOMER1 mRNA and circRNAs variants among $\mathrm{ABC}$ stage groups and Braak stage. Univariate general linear model was used to study the proportions between HOMER1 RNA variants expression levels in AD versus control samples. Previously, the values of expression levels were transformed by using $\log _{10}(X)$ to meet the conditions of normality. Differences in methylation levels between two bisulfite cloning sequencing groups was evaluated with Mann-Whitney $U$ test. Spearman test was used to assess correlation between continuous variables. GraphPad Prism version 6.00 for Windows (GraphPad Software, La Jolla, CA, USA) was used to draw graphs except for methylation figures that were drawn by QUMA software.

Supplementary Materials: The following are available online at https: / www.mdpi.com/article / 10.3390/ijms22179205/s1, Supplemental Figure S1: HOMER1 RNA variants expression. Supplemental Figure S2: HOMER1 linear RNA and circRNA expression across AD stage in female group. Supplemental Figure S3: The decrease in expression of the different HOMER1 variants is proportional within AD female cases. Supplemental Figure S4: HOMER1 B/C protein decreased in human entorhinal cortex in Alzheimer's disease. Supplemental Table S1: Brain sample set characteristics. Supplemental Table S2: Summary of age and gender characteristics of subjects included in the study. 
Author Contributions: A.U.-C. contributed to the study concept and design, running of the experiments, acquisition of the data, analysis and interpretation of the data, statistical analysis, figure drawing and drafting/revising of the manuscript for content. J.S.-R.d.G. contributed to the analysis and interpretation of the data (amyloid deposits), sorting of the patients into different stages, and acquisition of the image data. M.R. (Maitane Robles) contributed to the running of the experiments and acquisition of the data. M.R. (Miren Roldan) contributed to the acquisition of the data. B.A. contributed to the acquisition of the data. M.V.Z. participated in the revision of the subject diagnosis and classification of patients. I.B.-L. contributed to the study concept and design. M.M. contributed to the drafting/revising of the manuscript for content, study concept and design, analysis and interpretation of the data, study supervision, and obtaining the funding. All authors have read and agreed to the published version of the manuscript.

Funding: This work was supported by the Spanish Government through grants from the Institute of Health Carlos III (FIS PI20/01701). In addition, A.U.-C. received two grants “Doctorados industriales 2018-2020" and "Contrato predoctoral en investigación en ciencias y tecnologías de la salud en el periodo 2019-2022", both of them founded by the Government of Navarra. B.A. is supported by a PFIS fellowship from the Spanish Government (FI18/00150) and M.M. received a grant "Programa de intensificación" (LCF/PR/PR15/51100006) funded by Fundación Bancaria "la Caixa" and Fundación Caja-Navarra and "Contrato de intensificación" from the Institute of Health Carlos III (INT19/00029).

Institutional Review Board Statement: Not applicable.

Informed Consent Statement: Not applicable.

Data Availability Statement: Not applicable.

Acknowledgments: We want to kindly thank Mónica Enguita Germán (Methodology Department of Navarrabiomed, technical support) and Isabel Gil-Aldea (Navarrabiomed Biobank, technical support) for their help. Finally, we are very grateful to the patients and relatives that generously donated the brain tissue to the Navarrabiomed Biobank.

Conflicts of Interest: The authors declare that they have no competing interest.

\section{References}

1. Mayeux, R.; Stern, Y. Epidemiology of Alzheimer disease. Cold Spring Harb Perspect Med. 2012, 2, a006239. [CrossRef] [PubMed]

2. Reitz, C.; Mayeux, R. Alzheimer disease: Epidemiology, diagnostic criteria, risk factors and biomarkers. Biochem. Pharmacol. 2014, 88, 640-651. [CrossRef] [PubMed]

3. Jeong, S. Molecular and Cllular Basis of Neurodegeneration in Alzheimer's Disease. Mol. Cells 2017, 40, 613-620. [CrossRef] [PubMed]

4. Millan, M.J. The epigenetic dimension of Alzheimer's disease: Causal, consequence, or curiosity? Dialogues Clin. Neurosci. 2014, 16, 373-393. [PubMed]

5. Bukke, V.N.; Archana, M.; Villani, R.; Romano, A.D.; Wawrzyniak, A.; Balawender, K.; Orkisz, S.; Beggiato, S.; Serviddio, G.; Cassano, T. The Dual Role of Glutamatergic Neurotransmission in Alzheimer's Disease: From Pathophysiology to Pharmacotherapy. Int. J. Mol. Sci. 2020, 21, 7452. [CrossRef] [PubMed]

6. McDaid, J.; Mustaly-Kalimi, S.; Stutzmann, G.E. Ca2+ dyshomeostasis disrupts neuronal and synaptic function in Alzheimer's disease. Cells 2020, 9, 2655. [CrossRef] [PubMed]

7. Yamamoto, K.; Ueta, Y.; Wang, L.; Yamamoto, R.; Inoue, N.; Inokuchi, K.; Aiba, A.; Yonekura, H.; Kato, N. Suppression of a neocortical potassium channel activity by intracellular amyloid- $\beta$ and its rescue with Homer1a. J. Neurosci. 2011, 31, 11100-11109. [CrossRef]

8. Luo, P.; Li, X.; Fei, Z.; Poon, W. Scaffold protein Homer 1: Implications for neurological diseases. Neurochem. Int. 2012, 61, 731-738. [CrossRef]

9. Clifton, N.E.; Trent, S.; Thomas, K.L.; Hall, J. Regulation and Function of Activity-Dependent Homer in Synaptic Plasticity. Mol. Neuropsychiatry 2019, 5, 147-161. [CrossRef]

10. Shiraishi-Yamaguchi, Y.; Furuichi, T. The Homer family proteins. Genome Biol. 2007, 8, 206. [CrossRef]

11. Zimmerman, A.J.; Hafez, A.K.; Amoah, S.K.; Rodriguez, B.A.; Dell'Orco, M.; Lozano, E.; Hartley, B.J.; Alural, B.; Lalonde, J.; Chander, P.; et al. A psychiatric disease-related circular RNA controls synaptic gene expression and cognition. Mol. Psychiatry 2020, 25, 2712-2727. [CrossRef]

12. Kent, W.J.; Sugnet, C.W.; Furey, T.S.; Roskin, K.M.; Pringle, T.H.; Zahler, A.M.; Haussler, D. The human genome browser at UCSC. Genome Res. 2002, 12, 996-1006. [CrossRef]

13. Navarro Gonzalez, J.; Zweig, A.S.; Speir, M.L.; Schmelter, D.; Rosenbloom, K.R.; Raney, B.J.; Powell, C.C.; Nassar, L.R.; Maulding, N.D.; Lee, C.M.; et al. The UCSC Genome Browser database: 2021 update. Nucleic Acids Res. 2021, 49, D1046-D1057. [CrossRef] 
14. Niibori, Y.; Hayashi, F.; Hirai, K.; Matsui, M.; Inokuchi, K. Alternative poly(A) site-selection regulates the production of alternatively spliced vesl-1/homer1 isoforms that encode postsynaptic scaffolding proteins. Neurosci. Res. 2007, 57, 399-410. [CrossRef] [PubMed]

15. Jardin, I.; López, J.J.; Berna-Erro, A.; Salido, G.M.; Rosado, J.A. Homer proteins in Ca ${ }^{2+}$ entry. IUBMB Life 2013, 65, 497-504. [CrossRef] [PubMed]

16. Xiao, M.S.; Ai, Y.; Wilusz, J.E. Biogenesis and Functions of Circular RNAs Come into Focus. Trends Cell Biol. 2020, 30, 226-240. [CrossRef] [PubMed]

17. Vicens, Q.; Westhof, E. Biogenesis of Circular RNAs. Cell 2014, 159, 13-14. [CrossRef]

18. Bolha, L.; Ravnik-Glavac, M.; Glavac, D. Circular RNAs: Biogenesis, Function, and a Role as Possible Cancer Biomarkers. Int. J. Genom. 2017, 2017, 6218353. [CrossRef] [PubMed]

19. Memczak, S.; Jens, M.; Elefsinioti, A.; Torti, F.; Krueger, J.; Rybak, A.; Maier, L.; Mackowiak, S.D.; Gregersen, L.H.; Munschauer, M.; et al. Circular RNAs are a large class of animal RNAs with regulatory potency. Nature 2013, 495, 333-338. [CrossRef]

20. Rybak-Wolf, A.; Stottmeister, C.; Glazar, P.; Jens, M.; Pino, N.; Giusti, S.; Hanan, M.; Behm, M.; Bartok, O.; Ashwal-Fluss, R.; et al. Circular RNAs in the Mammalian Brain Are Highly Abundant, Conserved, and Dynamically Expressed. Mol. Cell 2015, 58, 870-885. [CrossRef]

21. Hanan, M.; Soreq, H.; Kadener, S. CircRNAs in the brain. RNA Biol 2017, 14, 1028-1034. [CrossRef]

22. Chen, W.; Schuman, E. Circular RNAs in Brain and Other Tissues: A Functional Enigma. Trends Neurosci. 2016, 39, 597-604. [CrossRef] [PubMed]

23. You, X.; Vlatkovic, I.; Babic, A.; Will, T.; Epstein, I.; Tushev, G.; Akbalik, G.; Wang, M.; Glock, C.; Quedenau, C.; et al. Neural circular RNAs are derived from synaptic genes and regulated by development and plasticity. Nat. Neurosci. 2015, 18, 603-610. [CrossRef]

24. Dube, U.; Del-Aguila, J.L.; Li, Z.; Budde, J.P.; Jiang, S.; Hsu, S.; Ibanez, L.; Fernandez, M.V.; Farias, F.; Norton, J.; et al. An atlas of cortical circular RNA expression in Alzheimer disease brains demonstrates clinical and pathological associations. Nat. Neurosci. 2019, 22, 1903-1912. [CrossRef]

25. Cervera-Carles, L.; Dols-Icardo, O.; Molina-Porcel, L.; Alcolea, D.; Cervantes-Gonzalez, A.; Muñoz-Llahuna, L.; Clarimon, J. Assessing circular RNAs in Alzheimer's disease and frontotemporal lobar degeneration. Neurobiol. Aging 2020, 92, 7-11. [CrossRef] [PubMed]

26. Lo, I.; Hill, J.; Vilhjálmsson, B.J.; Kjems, J. Linking the association between circRNAs and Alzheimer's disease progression by multi-tissue circular RNA characterization. RNA Biol. 2020, 17, 1789-1797. [CrossRef] [PubMed]

27. Dudekula, D.B.; Panda, A.C.; Grammatikakis, I.; De, S.; Abdelmohsen, K.; Gorospe, M. CircInteractome: A web tool for exploring circular RNAs and their interacting proteins and microRNAs. RNA Biol. 2016, 13, 34-42. [CrossRef]

28. Clifton, N.E.; Cameron, D.; Trent, S.; Sykes, L.H.; Thomas, K.L.; Hall, J. Hippocampal Regulation of Postsynaptic Density Homer1 by Associative Learning. Neural. Plast 2017, 2017, 5959182. [CrossRef]

29. Leber, S.L.; Llenos, I.C.; Miller, C.L.; Dulay, J.R.; Haybaeck, J.; Weis, S. Homer1a protein expression in schizophrenia, bipolar disorder, and major depression. J. Neural. Transm. 2017, 124, 1261-1273. [CrossRef]

30. Matosin, N.; Fernandez-Enright, F.; Lum, J.S.; Engel, M.; Andrews, J.L.; Gassen, N.C.; Wagner, K.V.; Schmidt, M.V.; Newell, K.A. Molecular evidence of synaptic pathology in the CA1 region in schizophrenia. NPJ Schizophr. 2016, 2, 16022. [CrossRef]

31. Murotomi, K.; Takagi, N.; Muroyama, A.; Kaji, N.; Takeo, S.; Tanonaka, K. Transient focal cerebral ischemia differentially decreases Homer1a and 1b/c contents in the postsynaptic density. Neurosci. Lett. 2012, 515, 92-96. [CrossRef] [PubMed]

32. Forner, S.; Baglietto-Vargas, D.; Martini, A.C.; Trujillo-Estrada, L.; LaFerla, F.M. Synaptic Impairment in Alzheimer's Disease: A Dysregulated Symphony. Trends Neurosci. 2017, 40, 347-357. [CrossRef] [PubMed]

33. Dickey, C.A.; Loring, J.F.; Montgomery, J.; Gordon, M.N.; Eastman, P.S.; Morgan, D. Selectively reduced expression of synaptic plasticity-related genes in amyloid precursor protein + presenilin-1 transgenic mice. J. Neurosci. 2003, 23, 52195226. [CrossRef] [PubMed]

34. Viña, J.; Lloret, A. Why women have more Alzheimer's disease than men: Gender and mitochondrial toxicity of amyloid-beta peptide. J. Alzheimers Dis. 2010, 20 (Suppl. 2), S527-S533. [CrossRef] [PubMed]

35. Scheyer, O.; Rahman, A.; Hristov, H.; Berkowitz, C.; Isaacson, R.S.; Diaz Brinton, R.; Mosconi, L. Female Sex and Alzheimer's Risk: The Menopause Connection. J. Prev. Alzheimers Dis. 2018, 5, 225-230. [CrossRef]

36. Hilton, G.D.; Nunez, J.L.; Bambrick, L.; Thompson, S.M.; McCarthy, M.M. Glutamate-mediated excitotoxicity in neonatal hippocampal neurons is mediated by mGluR-induced release of $\mathrm{Ca}++$ from intracellular stores and is prevented by estradiol. Eur. J. Neurosci. 2006, 24, 3008-3016. [CrossRef]

37. Counts, S.E.; Che, S.; Ginsberg, S.D.; Mufson, E.J. Gender differences in neurotrophin and glutamate receptor expression in cholinergic nucleus basalis neurons during the progression of Alzheimer's disease. J. Chem. Neuroanat. 2011, 42, 111-117. [CrossRef]

38. Mazure, C.M.; Swendsen, J. Sex differences in Alzheimer's disease and other dementias. Lancet Neurol. 2016, 15, 451-452. [CrossRef] 
39. Deming, Y.; Dumitrescu, L.; Barnes, L.L.; Thambisetty, M.; Kunkle, B.; Gifford, K.A.; Bush, W.S.; Chibnik, L.B.; Mukherjee, S.; De Jager, P.L.; et al. Sex-specific genetic predictors of Alzheimer's disease biomarkers. Acta Neuropathol. 2018, 136, 857-872. [CrossRef]

40. Iasevoli, F.; Buonaguro, E.F.; Sarappa, C.; Marmo, F.; Latte, G.; Rossi, R.; Eramo, A.; Tomasetti, C.; de Bartolomeis, A. Regulation of postsynaptic plasticity genes' expression and topography by sustained dopamine perturbation and modulation by acute memantine: Relevance to schizophrenia. Prog. Neuropsychopharmacol. Biol. Psychiatry 2014, 54, 299-314. [CrossRef]

41. De Bartolomeis, A.; Sarappa, C.; Buonaguro, E.F.; Marmo, F.; Eramo, A.; Tomasetti, C.; Iasevoli, F. Different effects of the NMDA receptor antagonists ketamine, MK-801, and memantine on postsynaptic density transcripts and their topography: Role of Homer signaling, and implications for novel antipsychotic and pro-cognitive targets in psychosis. Prog. Neuropsychopharmacol. Biol. Psychiatry 2013, 46, 1-12. [CrossRef]

42. Brouillette, J.; Young, D.; During, M.J.; Quirion, R. Hippocampal gene expression profiling reveals the possible involvement of Homer1 and GABA(B) receptors in scopolamine-induced amnesia. J. Neurochem. 2007, 102, 1978-1989. [CrossRef]

43. Ju, Y.E.; Lucey, B.P.; Holtzman, D.M. Sleep and Alzheimer disease pathology-A bidirectional relationship. Nat. Rev. Neurol. 2014, 10, 115-119. [CrossRef]

44. Mander, B.A.; Marks, S.M.; Vogel, J.W.; Rao, V.; Lu, B.; Saletin, J.M.; Ancoli-Israel, S.; Jagust, W.J.; Walker, M.P. $\beta$-amyloid disrupts human NREM slow waves and related hippocampus-dependent memory consolidation. Nat. Neurosci. 2015, 18, 1051-1057. [CrossRef]

45. Irwin, M.R.; Vitiello, M.V. Implications of sleep disturbance and inflammation for Alzheimer's disease dementia. Lancet Neurol. 2019, 18, 296-306. [CrossRef]

46. Cordone, S.; Annarumma, L.; Rossini, P.M.; De Gennaro, L. Sleep and $\beta$-Amyloid Deposition in Alzheimer Disease: Insights on Mechanisms and Possible Innovative Treatments. Front. Pharmacol. 2019, 10, 695. [CrossRef] [PubMed]

47. Sato, S.; Bunney, B.G.; Vawter, M.P.; Bunney, W.E.; Sassone-Corsi, P. Homer1a Undergoes Bimodal Transcriptional Regulation by CREB and the Circadian Clock. Neuroscience 2020, 434, 161-170. [CrossRef] [PubMed]

48. Maret, S.; Dorsaz, S.; Gurcel, L.; Pradervand, S.; Petit, B.; Pfister, C.; Hagenbuchle, O.; O’Hara, B.F.; Franken, P.; Tafti, M. Homer1a is a core brain molecular correlate of sleep loss. Proc. Natl. Acad. Sci. USA 2007, 104, 20090-20095. [CrossRef] [PubMed]

49. Fjell, A.M.; Sederevicius, D.; Sneve, M.H.; de Lange, A.G.; Bråthen, A.C.; Idland, A.V.; Watne, L.O.; Wang, Y.; Reinbold, C.; Dobricic, V.; et al. Self-reported Sleep Problems Related to Amyloid Deposition in Cortical Regions with High HOMER1 Gene Expression. Cereb Cortex 2020, 30, 2144-2156. [CrossRef]

50. Ferreira, H.J.; Davalos, V.; de Moura, M.C.; Soler, M.; Perez-Salvia, M.; Bueno-Costa, A.; Setien, F.; Moran, S.; Villanueva, A.; Esteller, M. Circular RNA CpG island hypermethylation-associated silencing in human cancer. Oncotarget 2018, 9 , 29208-29219. [CrossRef]

51. Mahan, A.L.; Mou, L.; Shah, N.; Hu, J.H.; Worley, P.F.; Ressler, K.J. Epigenetic modulation of Homer1a transcription regulation in amygdala and hippocampus with pavlovian fear conditioning. J. Neurosci. 2012, 32, 4651-4659. [CrossRef]

52. Sun, L.; Verkaik-Schakel, R.N.; Biber, K.; Plösch, T.; Serchov, T. Antidepressant treatment is associated with epigenetic alterations of Homer1 promoter in a mouse model of chronic depression. J. Affect. Disord. 2021, 279, 501-509. [CrossRef]

53. Altuna, M.; Urdánoz-Casado, A.; Sánchez-Ruiz de Gordoa, J.; Zelaya, M.V.; Labarga, A.; Lepesant, J.M.J.; Roldán, M.; BlancoLuquin, I.; Perdones, Á.; Larumbe, R.; et al. DNA methylation signature of human hippocampus in Alzheimer's disease is linked to neurogenesis. Clin. Epigenetics 2019, 11, 91. [CrossRef] [PubMed]

54. Zusso, M.; Barbierato, M.; Facci, L.; Skaper, S.D.; Giusti, P. Neuroepigenetics and Alzheimer's Disease: An Update. J. Alzheimers Dis. 2018, 64, 671-688. [CrossRef]

55. Bell, J.E.; Alafuzoff, I.; Al-Sarraj, S.; Arzberger, T.; Bogdanovic, N.; Budka, H.; Dexter, D.T.; Falkai, P.; Ferrer, I.; Gelpi, E.; et al. Management of a twenty-first century brain bank: Experience in the BrainNet Europe consortium. Acta Neuropathol. 2008, 115, 497-507. [CrossRef]

56. Montine, T.J.; Phelps, C.H.; Beach, T.G.; Bigio, E.H.; Cairns, N.J.; Dickson, D.W.; Duyckaerts, C.; Frosch, M.P.; Masliah, E.; Mirra, S.S.; et al. National Institute on Aging-Alzheimer's Association guidelines for the neuropathologic assessment of Alzheimer's disease: A practical approach. Acta Neuropathol. 2012, 123, 1-11. [CrossRef] [PubMed]

57. Braak, H.; Alafuzoff, I.; Arzberger, T.; Kretzschmar, H.; Del Tredici, K. Staging of Alzheimer disease-associated neurofibrillary pathology using paraffin sections and immunocytochemistry. Acta Neuropathol. 2006, 112, 389-404. [CrossRef] [PubMed]

58. Mirra, S.S.; Heyman, A.; McKeel, D.; Sumi, S.M.; Crain, B.J.; Brownlee, L.M.; Vogel, F.S.; Hughes, J.P.; van Belle, G.; Berg, L. The Consortium to Establish a Registry for Alzheimer's Disease (CERAD). Part II. Standardization of the neuropathologic assessment of Alzheimer's disease. Neurology 1991, 41, 479-486. [CrossRef]

59. Vandesompele, J.; De Preter, K.; Pattyn, F.; Poppe, B.; Van Roy, N.; De Paepe, A.; Speleman, F. Accurate normalization of real-time quantitative RT-PCR data by geometric averaging of multiple internal control genes. Genome Biol. 2002, 3, RESEARCH0034. [CrossRef] [PubMed]

60. Casper, J.; Zweig, A.S.; Villarreal, C.; Tyner, C.; Speir, M.L.; Rosenbloom, K.R.; Raney, B.J.; Lee, C.M.; Lee, B.T.; Karolchik, D.; et al. The UCSC Genome Browser database: 2018 update. Nucleic Acids Res. 2018, 46, D762-d769. [CrossRef]

61. Kent, W.J. BLAT-The BLAST-like alignment tool. Genome Res. 2002, 12, 656-664. [CrossRef] [PubMed] 
62. Li, L.C.; Dahiya, R. MethPrimer: Designing primers for methylation PCRs. Bioinformatics 2002, 18, 1427-1431. [CrossRef] [PubMed]

63. Kumaki, Y.; Oda, M.; Okano, M. QUMA: Quantification tool for methylation analysis. Nucleic Acids Res. 2008, 36, W170-W175. [CrossRef] [PubMed] 